\title{
Familial café au lait spots: a variant of neurofibromatosis type 1
}

Dvorah Abeliovich, Zully Gelman-Kohan, Shira Silverstein, Israela Lerer, Juan Chemke, Saul Merin, Joel Zlotogora

\begin{abstract}
Café au lait spots (CALS) are a frequent and one of the early manifestations of neurofibromatosis 1 (NF1). However, there are patients with isolated CALS who do not meet the diagnostic criteria for NFI. There are several reports of families in which CALS are inherited as an autosomal dominant trait, without any other features of NFI. In one reported family with dominantly inherited CALS linkage to the NF1 locus was ruled out. In order to elucidate the relationship between familial CALS and NF1 further, we performed a linkage analysis in a large kindred with 11 subjects with CALS in three generations and established close linkage between CALS and five NF1 intragenic polymorphisms. We propose that in this family the trait of CALS is allelic to NF1, it is fully penetrant, and it does not confer a risk of other NF1 symptoms.
\end{abstract}

( $($ Med Genet 1995;32:985-986)

Neurofibromatosis type 1 (NF1) is an autosomal dominant disorder with a high degree of variation ${ }^{1}$; some of the manifestations are age dependent and progressive. The diagnostic criteria of NF1 were formulated by the NIH Consensus Development Conference on Neurofibromatosis $(1988)^{2}$ and include two or more of the following manifestations: café au lait spots (CALS), neurofibromas of any type, Lisch nodules, axillary freckling, optic glioma, a distinctive osseous lesion, and a first degree relative with.NF1. Café au lait spots and axillary freckling are present at birth and increase in number and size with age; cutaneous neurofibromas tend to appear in the second decade. Lisch nodules are frequent in adults and represent an important aid in NF1 diagnosis. It was suggested by Riccardi ${ }^{1}$ that patients who do not fit into NF1 (or NF2) should be classified into NF3 to NF7. NF6 was suggested for families with dominantly inherited café au lait spots as the only manifestation of $\mathrm{NF}^{3}$ Since the mapping and cloning of the NF1 gene to chromosome $17 \mathrm{q} 11.2,{ }^{45}$ it is possible to relate the variant forms of NF1 to the NF1 gene. In one family with dominant CALS no linkage to the NF1 gene was found. ${ }^{6}$ We present another family with dominantly inherited, isolated CALS. In this family the trait is closely linked to the NF1 gene.

\section{Family report}

The proband (III 1 , figure) was referred to us through the Paediatric Neurology Department with the presumptive diagnosis of neurofibromatosis type 1 . She presented with multiple $(>6)$ café au lait spots of different sizes $\left(>0.5 \mathrm{~cm}^{2}\right)$ all over her body. At that time she was 7 years old, her psychomotor development was normal, and she did not have any other abnormal clinical findings. On ocular examination no Lisch nodules were found. In her family (figure), her father (II-1) and two of her three sibs (III.3 and III.4) had CALS but otherwise normal physical and ocular examinations. Many other family members, including the paternal grandmother (I-2), had multiple CALS of various sizes ( $>6$ and $\left.>0.5 \mathrm{~cm}^{2}\right)$. The paternal family is Jewish of Iranian ancestry.

The prepubertal patients showed neonatal CALS and there is no information for the adults. None of the patients had either axillary or inguinal freckling or neurofibromas. Whenever it was possible physical and ocular examination by slit lamp to trace Lisch nodules were performed; some subjects also had a CT scan of the brain. The clinical findings of the family members are summarised in the table.

\section{Methods and results}

DNA was prepared from peripheral blood samples using the standard procedure. Linkage analysis was performed with NF1 intragenic polymorphic markers as previously described. Lod scores were calculated using the LIPED program.

Fourteen family members, 10 of them with CALS, were typed with five polymorphic intragenic markers and the haplotype of the NF1 locus was constructed. The results are

Clinical findings in the family members

\begin{tabular}{|c|c|c|c|c|}
\hline & $C A L S$ & $C T$ findings & Lisch nodules & Age $(y)^{*}$ \\
\hline $\mathrm{I} \cdot 2$ & + & ND & $\mathrm{N}$ & 70 \\
\hline II $\cdot 1$ & + & ND & $\mathrm{N}$ & 45 \\
\hline II $\cdot 3$ & + & ND & $\mathrm{N}$ & 50 \\
\hline II. 5 & + & ND & $\mathbf{N}$ & 30 \\
\hline II 6 & - & ND & ND & 40 \\
\hline II. 7 & - & ND & ND & 48 \\
\hline II $\cdot 8$ & + & ND & $\mathrm{N}$ & 43 \\
\hline III $\cdot 1$ & + & $\mathrm{N}$ & $\mathrm{N}$ & 12 \\
\hline III $\cdot 2$ & - & ND & ND & 11 \\
\hline $\mathrm{III} \cdot 3$ & + & ND & $\mathbf{N}$ & 9 \\
\hline $\mathrm{III} \cdot 4$ & + & $\mathrm{N}$ & $\mathrm{N}$ & 1 \\
\hline III $\cdot 5$ & + & $\mathrm{N}$ & $\mathbf{N}$ & 16 \\
\hline $\mathrm{III} \cdot 6$ & + & ND & ND & 12 \\
\hline III. 7 & + & ND & $\mathrm{ND}$ & $>1$ \\
\hline III $\cdot 8$ & - & ND & ND & 10 \\
\hline
\end{tabular}

$\mathrm{N}=$ normal findings on CT scan and no Lisch nodules. $\mathrm{ND}=$ not done.

* Age at the time of examination. 


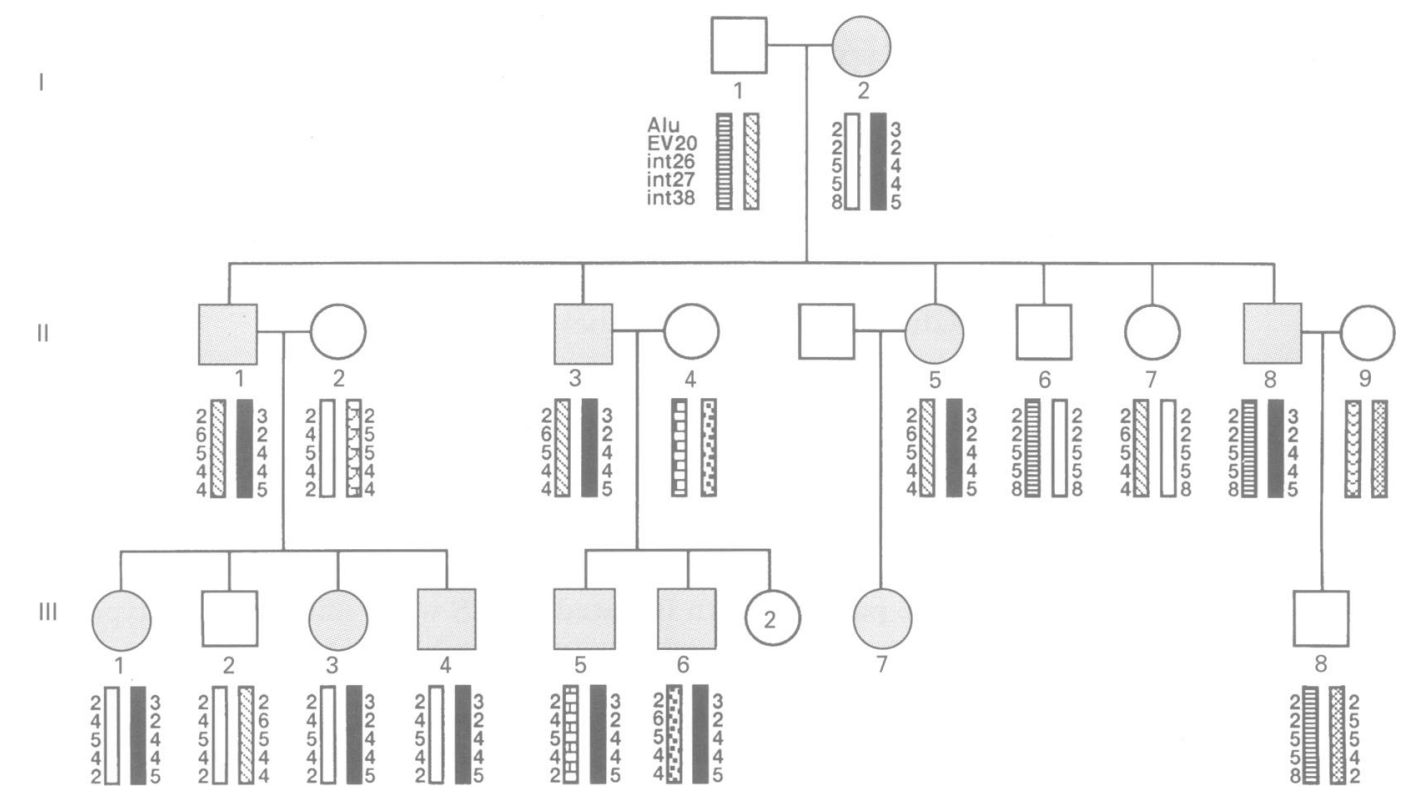

Pedigree of the family and the haplotypes of the NF1 alleles using NF1 intragenic polymorphic markers. The filled squares and circles indicate the presence of CALS. The haplotype in association with CALS is black.

presented in the figure. III.6 was not informative since his two haplotypes were identical to his father's haplotypes and his mother was not available for analysis. The calculated lod score for $\theta=0$ was $3 \cdot 61$, which strongly supports the linkage hypothesis.

\section{Discussion}

The variable manifestation of NF1 is intrafamilial as well as interfamilial. ${ }^{1}$ Several mechanisms that may account for this were suggested by Riccardi. ${ }^{8}$ Based on this observation the genetic counselling to families with NF1 is that the severity of the disease cannot be predicted. This is especially important when parents wish to make decisions about family planning and prenatal diagnosis. Familial traits such as CALS, that are an integral part of the clinical features of NF1, but do not meet the diagnostic criteria of NF1, raise the question of whether they are subtypes of NF1. This question may be answered by mutation analysis of the NF1 gene or by linkage analysis, provided that the family is large enough. If the trait is genetically classified as linked to the NF1 locus on chromosome 17 , the possible clinical variation should be addressed. These variant traits may shed light on the genotype-phenotype correlation in NF1 and may represent a new class of mutations that have a partial effect.

In at least one family, it was shown that familial CALS was not linked to the NFI gene. ${ }^{6}$
In the family that we present in this report the trait of CALS is in close linkage to the NF1 gene (lod score $>3 \cdot 6$ ). All subjects who had inherited the CALS bearing haplotype had CALS, and it was the only sign of NF1 regardless of the age of the patient (from a few months to old age). We therefore concluded that in this family the CALS trait is allelic to NF1 and is fully penetrant. The genetic counselling to the members of the family was that the risk for developing other NF1 signs is minimal in carriers. The family that we describe and the one described by Charrow et $a l^{6}$ show genetic heterogeneity of the CALS trait. In some cases it may be a part of the clinical spectrum of NF1 while in others it is a distinct trait caused by a different gene(s).

1 Riccardi VM. Neurofibromatosis: phenotype, natural history and pathogenesis. 2nd ed. Baltimore: Johns Hopkins University Press, 1992

2 National Institute of Health Consensus Development Conference. Neurofibromatosis. Arch Neurol 1988;45:575-8.

3 Riccardi VM. Neurofibromatosis: clinical heterogeneity. Curr Concepts Cancer 1982;7:1-35.

4 Cawthon RM, Weiss R, Xu G, et al. A major segment of the neurofibromatosis type 1 gene: cDNA sequence, genomic structure, and point mutations. Cell 1990;62:193-201.

5 Wallace MR, Collins FS. Molecular genetics of von Reckinghausen neurofibromatosis. Adv Hum Genet 1991;20 267-307.

6 Charrow J, Listernick R, Ward K. Autosomal dominant multiple cafe-au-lait spots and neurofibromatosis-1: evidence of non-linkage. Am $\mathcal{F}$ Med Genet 1993;45:606-8.

7 Elyakim S, Lerer I, Zlotogora J, et al. Neurofibromatosis type 1 (NF1) in Israeli families: linkage analysis as a diagnostic tool. Am ₹ Med Genet 1994;53:325-34.

8 Riccardi VM. Invited editorial. Genotype, malleotype, phenotype, and randomness: lessons from neurofibromatosis(NF1). Am ₹ Hum Genet 1993;53:301-4. 